\title{
Anticancer Agents in Combination with Statins
}

\author{
Mohammad Adnan, Kabir Imtiazul Mohammad and Mohammad Emdad Hossain Manik* \\ Department of Pharmacy, International Islamic University, Chittagong, Bangladesh
}

\begin{abstract}
Statins are 3-Hydroxy-3-methylgutaryl CoA (HMG CoA) reductase inhibitors and mainly used in cardiovascular diseases. However, they are also widely known for their anticancer activities mediated by antiproliferative, proapoptotic, anti-invasive, and radio sensitizing properties. They are tested alone in several clinical trials for their anticancer activity and the response in not satisfactory due to high dose requirements in humans. Tumor inhibitory concentration of statins is $10-100 \mu \mathrm{M}$ for different cancer cell lines when tested in vitro. But statins can cause anorexia and death in some individuals if concentration is reached to $20-25 \mu \mathrm{M}$ in serum. So, there is high risk factor. To avoid these unwanted harmful effects, we can give statins in combination with other chemotherapeutic drugs for synergism. It will reduce the concentration of statins in dosage, and can avoid unwanted toxic effects. When used along with the other chemo therapeutic agents like prenylation inhibitors, NSAIDS and standard chemotherapeutic agents, they have shown much better results at lower doses with little or no toxicity.
\end{abstract}

\section{Keywords: Statins; Cancer; Vitamins; Doxorubicin; PSA; RAS}

\section{Introduction}

Statins are well known drugs to reduce cholesterol levels in the body by inhibiting HMG CoA reductase enzyme. Inhibition of HMG-CoA reductase is rate limiting step in mevalonate pathway. Intermediate and downstream products of this pathway including isoprenyl sub units are essential for critical cellular functions such as membrane integrity, cell signaling, protein synthesis, and cell cycle progression [1]. Cancer cells use this pathway to upregulate key essential molecules for tumor initiation, growth, and metastasis. By targeting the mevalonate pathway, statins exert growth inhibitory activity in cancer cells evident from in vitro and animal studies [2]. Protein prenylation is necessary for anchoring of proteins to cell membranes, protein-protein interactions and localization [3]. The isoprenoid intermediates of mevalonate pathway, farnesyl and geranyl-geranyl pyrophosphate are essential for post-translational modification of variety of intracellular proteins including Rho, Rac, and Ras. The two isoprenyl units activate different proteins in cells mediating cell proliferation and survival [4].

Post translational modifications of proteins determine their functionality in eukaryotic cells. Proteins undergo different kinds of post translational modification and lipid modifications are one of them $[5,6]$. It is found that prenylation (lipid modification) of proteins like Ras activates them and lead to cancer [2,7-9]. Prenylation occurs at carboxy terminal of protein and aids in binding or docking of the protein to the cell membrane or other cellular organelles. Prenylated proteins increase uncontrolled proliferation of cells and decrease apoptotic factors. Inhibition of specific proteins' prenylation may show better therapeutic values in cancer patients $[10,11]$.

According to clinical studies, continuous supplementation of statins for more than 5 years reduced colorectal cancer risk by $47 \%$. But, the patient factors like age, sex and ethnic groups are to be taken into consideration for better outcome [12]. In a similar study, statins were administered for a period of 4 years and it decreased cancer occurrence by $20 \%$ [13]. However, limitations are suggested to use statins for prolonged period of time due to their nonspecific toxicities in body. The high dose of statins may outweigh unwanted effects to the therapeutic outcomes [14]. As statins are critical regulators of many cell essential proteins and their activation, increasing evidence is available to show their use in cancer prevention and treatment. Statins demonstrated their anticancer activity in melanoma, glioma, neuroblastoma, and leukemia cell lines [1].
Cohort studies (pharmacoepidemiologic survey) in which patients were analyzed based upon their statins use indicate their pharmacological benefit of improving cancer patient survival [15]. More than 300,000 patients with cancer were identified for their statins use in a period and divided into groups as statin users, nonstatin users and nonusers. Leukemia, lung and renal cancer patients who have taken statins before diagnosis showed high overall survival rate. At the same time, statins and bisphosphonates combination used group of patients were also associated with increased survival compared to that of no treatment group. This indicates that the statins use alone or in combination can affect isoprenylation of compounds inside the cell to exert their anticancer activity [15]. Further clinical investigation is needed to better support the data and the pharmacological benefit of statins.

\section{Statins with Prenylation Inhibitors}

Statins and prenylation inhibitors are the two different drugs used to inhibit the prenylation of proteins at different levels. The prenylated proteins which are important in cancer include Ras, Heterotrimeric $\mathrm{G}$ proteins and Rab proteins [16,17]. When statins and prenylation inhibitors are used in combination, statins decrease the pool of isoprenyl subunits in the cell and at the same time prenylation inhibitors decrease transfer of any isoprenyl units to the proteins. This action is synergistic $[18,19]$. Statins and prenylation inhibitors are acting at same pathway but at different stages. Synergistic combination also decreases the dose of individual compounds required for showing the therapeutic action and lesser associated toxicities.

Ras is a small G protein. The prenylation of Ras is important for its malignant action [20,21]. Ras undergoes lipid modifications (prenylation) at the carboxy terminal and further its oncogenic activity of Ras is increased leading to cancer. Ras undergoes two types of lipid

*Corresponding author: Md Emdad Hossain Manik, International Islamic University, Chittagong, Bangladesh, Tel: 01557-849422; E-mail: ehmanik.me@gmail.com

Received June 17, 2017; Accepted July 04, 2017; Published July 12, 2017

Citation: Adnan M, Mohammad KI, Manik MEH (2017) Anticancer Agents in Combination with Statins. J Bioequiv Availab 9: 463-466. doi: 10.4172/jbb.1000345

Copyright: (c) 2017 Adnan M, et al. This is an open-access article distributed under the terms of the Creative Commons Attribution License, which permits unrestricted use, distribution, and reproduction in any medium, provided the original author and source are credited. 
modifications; they are farnesylation and geranylgeranylation [22]. Inhibition of Ras prenylation leads to anticancer activity. Farnesyl Transferase Inhibitors (FTIs) act competitively with farnesyl transferases and inhibit the farnesyl group attachment to the proteins and block the protein activity. FTIs can inhibit farnesylation of Ras, Rab and different proteins. FTIs inhibit the growth of Ras-dependent tumor cells [23,24]. And also, FTIs reduce Vascular Endothelial Growth Factor (VEGF) expression in mice and so reduces angiogenesis in cancer [25,26]. Statins when tested in clinical trials, the blood concentration was achieved in between 0.1-3.9 $\mu \mathrm{M}$ [27]. But concentrations above $3.9 \mu \mathrm{M}$ are essential for anticancer activity of Statins. When given with FTIs the combination gave better therapeutic results in different types of cancers.

Cancer is heterogeneous group diseases and can originate from any part of the body [28-31]. It consists of uncontrolled proliferated cells that vary in morphology, biology, and response to therapy [32,33]. Even there are multiple treatment options for cancer, they are still not sufficient to treat all the types of cancer completely without tumor relapse, recurrence or metastasis. During progression, cancer involves several mutations and abnormalities resulting in multiple clones in same tumor [34-38]. Hence combination treatment is one of the better options to target the tumor at multiple points at same time. GTIs like GGTI-2Z [(5-nitrofuran2-yl)methyl-(2Z,6E,10E)-3,7,11,15-tetramethylhexadeca-2,6,10,14tetraenyl-4-chlorobutyl(methyl)phosphoramidate] were developed and tested in vitro with combination of Lovastatin [3]. GGTI-2Z is a geranylgeranyl phosphate derivative. This combination was able to inhibit the proliferation of STS-26T malignant peripheral nerve sheath tumor cells synergistically. The inhibition was due to the arrest of G0/ G1 phase of cell cycle.

\section{Statins with $\gamma$-tocotrienol}

Vitamin E consists of eight isoforms and $\gamma$-tocotrienol is one of them bearing potent antitumor activity when tested in vitro [39-41]. It has very little or no toxicity on normal cells and so can be used in cancer treatment safely. $\gamma$-tocotrienol also showed its anticancer activity in combination studies with statins and celecoxib [42]. The combination acts synergistically and can avoid the myotoxicity associated with high dose statins monotherapy. Statins and $\gamma$-tocotrienol both act on HMGCoA pathway. Statins are the inhibitors of HMG-CoA reductase enzyme and $\gamma$-tocotrienol causes down regulation of HMG-CoA by affecting post transcriptional modifications of enzyme [43]. Here, $\gamma$-tocotrienol showed its combination synergistic activity with simvastatin, lovastatin and mevastatin at low doses. Combination of tocotrienol with statins induced cell cycle is arrested at G1 phase, and decreased levels of cyclins and cyclin dependent kinases $[43,44]$. Combination of $\gamma$-tocotrienol with statins inhibited the cyclin D1, CDK2 and further hyperphosphorylated $\mathrm{Rb}$ protein. Cyclin D1 combines with CDK4 or CDK6 during the G1 to $\mathrm{S}$ transition phase, causes hyper phosphorylation of $\mathrm{Rb}$ protein. This leads to tumorigenesis [44]. In many breast cancers Cyclin D1 is over expressed [45]. As $\gamma$-tocotrienol with statins is reducing the levels of cyclin D1, this combination treatment may be a promising approach for treating breast cancer in women. This combination is also inhibiting the Akt and MAPK pathways. $\gamma$-tocotrienol along with statins is increasing the p27 expression and inhibiting the CDKs [44].

$\gamma$-tocotrienol also works in colon cancer cells synergistically with atorvastatin when tested in vitro $[46,47]$. This combination decreased the RhoA protein concentration in the cell membrane by inhibiting the geranylgeranylation of RhoA and caused cell cycle arrest. Membrane binding of RhoA is essential for G1 to $S$ phase transition of cells [48]. Instead of acting on RhoA protein, this combination also induced apoptosis by caspase 3 activation, PARP cleavage and DNA fragmentation.

\section{Statins with NSAIDS}

Non-steroidal Anti-inflammatory Agents (NSAIDS) are the cyclooxygenase inhibitors. Cyclooxygenase-2 (COX-2) inhibition can affect tumor cell survival, angiogenesis and metastasis [49,50]. NSAIDS also work through COX-independent mechanisms [51]. They can be used not only as anti-inflammatory agents but also as anticancer drugs, especially in colorectal cancer [52-54]. But the safety and efficacy are the two main factors which are not evaluated well $[55,56]$. NSAIDS can be used in cancers of breast, esophagus, stomach and prostate. Sulindac showed very good results when applied in adenomatous polyps [57]. It reduced the size and number of adenomatous polyps. Aspirin decreased the number of adenomas when tested in colorectal adenomas. However, NSAIDS required high dose administration to exert their anticancer activity. Long term use may cause gastro intestinal and cardiovascular adverse effects. To avoid this problem, we can combine the NSIADS with other chemotherapeutic agents and can reduce their dose [58].

In a population based case control study, aspirin is used in combination with atorvastatin and simvastatin. This combination reduced the risk of colorectal cancer by $62 \%$ if used for 5 or more years [58]. Moreover, NSAIDS with statins also lowers the risk of prostate cancer if used for 5 years [59]. In immune deficient mice injected with androgen independent PC-3 prostate cancer cells, celecoxib and atorvastatin delayed tumor occurrence significantly and also decreased the tumor size in mice bearing tumors [60]. In azoxymethane induced colon carcinogenesis rat model, the low dose combination of atorvastatin and celecoxib decreased the incidence of adenocarcinomas by $71 \%$ [61]. Atorvastatin combination with celecoxib decreased the membrane association of RhoA $[58,62]$. Here, atorvastatin is preventing the prenylation of RhoA and celecoxib is synergizing the effect and causing cell cycle arrest. This may be due to inhibition of negative effect of RhoA on p27Cip1/waf1 and p27Kip1. The treatment also induces apoptosis in cancer cells by inhibiting PDK1, and PI3K phosphorylation [62].

\section{Statins with Doxorubicin}

P-glycoprotein (P-gp) inhibitory property of statins is useful for its combination treatment with other chemo therapeutic agents [63]. P-gp is a glycosylated membrane associated multi drug resistant protein and responsible for the decreased drug concentration in multi-drug resistant cells [64]. P-gp mediated mechanism pumps drug out of the cell and the desired drug concentration inside the cell is regulated. Doxorubicin is an antibiotic and used in the chemotherapy of variety of cancers. When doxorubicin is used along with lovastatin in ovarian cancer cells, the statins sensitized the cells to doxorubicin and potentiated its anticancer activity synergistically. By blocking the drug efflux mediated by P-gp, Lovastatin increases the doxorubicin concentration inside the cells [63]. Simvastatin, atorvastatin or lovastatin inhibit the P-gp in high concentration $[65,66]$. Statins in combination with doxorubicin in human neuroblastoma cells (SH-SY5Y and STA-NB-10 cells) increased the concentration of doxorubicin inside the cancer cells [67]. Doxorubicin further caused the apoptosis. Lovastatin also decreased the P-gp levels in KGla-leukemia cells and further increased the daunorubicin concentration inside the cell [68].

Statins are also able to decrease the glycosylation of P-gp. P-gp is present in two forms, fully glycosylated species $(\sim 180 \mathrm{kDa})$ and core glycosylated species ( $\sim 140 \mathrm{kDa})$ [69]. Simvastatin and Atrovastatin are able to decrease the fully glycosylated form of P-gp. The core glycosylated 
P-gp cannot be folded properly and cannot transport the drug out of the cell. The glycosylation inhibitory action of statins may be due to the inhibition of dolichol synthesis [2]. So, statins decrease the P-gp content of the cell by two mechanisms.

\section{Statins with FOLFIRI}

In phase-II clinical study, simvastatin was tested in combination with FLOFIRI. FOLFIRI chemotherapy includes the administration of irinotecan, 5-fluorouracil and leucovorin. FOLFIRI treatment is used in colorectal cancer chemotherapy as a first line treatment. Combination increased the Time-to Progression (TTP) of colorectal cancer. At the same time, there is no increase in toxicity because of adding simvastatin [70].

\section{Statins Effect on PSA Levels}

Prostate Specific Antigen (PSA) is present in the serum of healthy men. PSA levels are increased beyond certain level in several prostate disorders or prostate cancer. It is evident that use of higher doses of statins can reduce the risk of advanced prostate cancer in men $[71,72]$. In a study, long term use of statins decreased the PSA levels by $42 \%$ [73]. Statins dependent decline in PSA levels may be the reason for reduced risk of advanced prostate cancer. Statins may reduce the risk of advanced prostate cancer by altering the prostate biology [74]. Reduction in the cholesterol bodies decreases the amount of membrane signaling domains in prostate [75]. Statins when given reduced the LDL levels by $28-41 \%$ and PSA levels are decreased significantly at the same time. Further studies are needed to understand whether the statins are influencing prostate cancer diagnosis by altering PSA levels.

\section{Conclusion}

Statins can be used as better chemotherapeutic agents in the future. Future directions should concentrate more on combination of statins with other anticancer agents, molecular targeted agents, and radiotherapy. They can also be used to prevent cancer occurrence, and in maintenance therapy.

\section{References}

1. Hindler K, Cleeland CS, Rivera E, Collard CD (2006) The role of statins in cancer therapy. Oncologist 11: 306-315.

2. Goldstein JL, Brown MS (1990) Regulation of the mevalonate pathway. Nature 343: 425-430.

3. Sane KM, Mynderse M, LaLonde DT, Dean IS, Wojtkowiak JW, et al. (2010) A novel geranylgeranyl transferase inhibitor in combination with lovastatin inhibits proliferation and induces autophagy in STS-26T MPNST cells. J Pharm Exp Ther 333: 23-33.

4. Crowell PL, Lin S, Vedejs E, Gould MN (1992) Identification of metabolites of the antitumor agentd-limonene capable of inhibiting protein isoprenylation and cell growth. Cancer Chemother Pharmacol 31: 205-212.

5. Zhang FL, Casey PJ (1996) Protein prenylation: molecular mechanisms and functional consequences. Ann Rev Biochem 65: 241-269.

6. Seabra MC (1998) Membrane association and targeting of prenylated Ras-like GTPases. Cell Signal 10: 167-172.

7. Casey PJ (1995) Protein lipidation in cell signaling. Science 268: 221-225.

8. Rando RR (1996) Chemical biology of protein isoprenylation/methylation. Biochim. Biophys Acta Lipids Lipid Metab 1300: 5-16.

9. Bos JL (1989) Ras oncogenes in human cancer: a review. Cancer Res 49: 4682-4689.

10. Gibbs JB, Oliff A (1997) The potential of farnesyltransferase inhibitors as cancer chemotherapeutics 1. Ann Rev Pharmacol Toxicol 37: 143-166.
11. Mazieres J, Pradines A, Favre G (2004) Perspectives on farnesyl transferase inhibitors in cancer therapy. Cancer Lett 206: 159-167.

12. Poynter JN, Gruber SB, Higgins PD, Almog R, Bonner JD, et al. (2005) Statins and the risk of colorectal cancer. N Engl J Med 352: 2184-2192.

13. Graaf MR, Beiderbeck AB, Egberts ACG, Richel DJ, Guchelaar HJ (2003) The risk of cancer in users of statins. $\mathrm{Br} J$ Clin Pharmacol 56: 466-467.

14. Baigent C, Keech A, Kearney PM, Blackwell L (2005) Efficacy and safety of cholesterol-lowering treatment: prospective meta-analysis of data from 90056 participants in 14 randomised trials of statins. The Lancet 366: 1267.

15. El-Refai SM, Brown JD, Arnold SM, Black EP, Leggas M (2017) Epidemiologic analysis along the mevalonate pathway reveals improved cancer survival in patients who receive statins alone and in combination with bisphosphonates. JCO Clin Cancer Inform.

16. Pereira-Leal JB, Seabra MC (2001) Evolution of the Rab family of small GTPbinding proteins. J Mol Biol 313: 889-901.

17. Brunsveld L, Kuhlmann J, Alexandrov K, Wittinghofer A, Goody RS, et al. (2006) Lipidated ras and rab peptides and proteins-synthesis, structure, and function. Angew Chem Int Ed Engl 45: 6622-6646.

18. Maeda T, Kawane T, Horiuchi N (2003) Statins augment vascular endothelia growth factor expression in osteoblastic cells via inhibition of protein prenylation. Endocrinology 144: 681-692.

19. Demierre MF, Higgins PD, Gruber SB, Hawk E, Lippman SM (2005) Statins and cancer prevention. Nat Rev Cancer 5: 930-942.

20. Slebos RJ, Kibbelaar RE, Dalesio O, Kooistra A, Stam J, et al. (1990) K-ras oncogene activation as a prognostic marker in adenocarcinoma of the lung. $\mathrm{N}$ Engl J Med 323: 561-565.

21. Kumar R, Sukumar S, Barbacid M (1990) Activation of ras oncogenes preceding the onset of neoplasia. Science 248: 1101-1104.

22. Konstantinopoulos PA, Karamouzis MV, Papavassiliou AG (2007) Posttranslational modifications and regulation of the RAS superfamily of GTPases as anticancer targets. Nat Rev Drug Discov 6: 541-555.

23. Sun J, Qian Y, Hamilton AD, Sebti SM (1995) Ras CAAX peptidomimetic FT 276 selectively blocks tumor growth in nude mice of a human lung carcinoma with K-Ras mutation and p53 deletion. Cancer Res 55: 4243-4247.

24. Rose WC, Lee FY, Fairchild CR, Lynch M, Monticello T, et al. (2001) Preclinical antitumor activity of BMS-214662, a highly apoptotic and novel farnesyltransferase inhibitor. Cancer Res 61: 7507-7517.

25. Cox AD, Garcia AM, Westwick JK, Kowalczyk JJ, Lewis MD, et al. (1994) The CAAX peptidomimetic compound B581 specifically blocks farnesylated, but not geranylgeranylated or myristylated, oncogenic ras signaling and transformation. J Biol Chem 269: 19203-19206.

26. Rak J, Mitsuhashi Y, Bayko L, Filmus J, Shirasawa S, et al. (1995) Mutant ras oncogenes upregulate VEGF/VPF expression: implications for induction and inhibition of tumor angiogenesis. Cancer Res 55: 4575-4580.

27. Thibault A, Samid D, Tompkins AC, Figg WD, Cooper MR, et al. (1996) Phase I study of lovastatin, an inhibitor of the mevalonate pathway, in patients with cancer. Clin Cancer Res 2: 483-491.

28. Bonner T, Ananthula S, Nordan J, Batth S, Marshall GD, et al. (2016) Geminin overexpression-dependent recruitment and crosstalk with mesenchymal stem cells enhances aggressiveness in triple-negative breast cancers. Clin Cancer Res.

29. Fisher R, Pusztai L, Swanton C (2013) Cancer heterogeneity: implications for targeted therapeutics. $\mathrm{Br} J$ Cancer 108: 479-485.

30. Martin JD, Fukumura D, Duda DG, Boucher Y, Jain RK (2016) Corrigendum: Reengineering the Tumor Microenvironment to Alleviate Hypoxia and Overcome Cancer Heterogeneity. Cold Spring Harbor Perspectives in Medicine 6.

31. Hosain SB, Liu YY (2015) Missense mutants of p53 tumor suppressor contributes to drug-resistance and epithelial-mesenchymal transition in colon cancer cells. Clin Cancer Res.

32. Ferlay J, Héry C, Autier P, Sankaranarayanan R (2010) Global burden of breast cancer. In: Breast cancer epidemiology. Springer, NY, USA pp: 1-19. 
Citation: Adnan M, Mohammad KI, Manik MEH (2017) Anticancer Agents in Combination with Statins. J Bioequiv Availab 9: 463-466. doi: 10.4172/ jbb.1000345

33. Ananthula S (2014) Bioavailability and bioequivalence issues associated with oral anticancer drugs and effect on drug market. J Bioequiv Availab 6: e56.

34. Ananthula S (2014) Mechanisms mediating tocotrienol derivative in vitro and in vivo anticancer effects and inhibition of compensatory responses to hypoxia in the highly malignant mouse+SA mammary cancer cells. University of Louisiana at Monroe, LA, USA.

35. Hollstein M, Sidransky D, Vogelstein B, Harris CC (1991) p53 mutations in human cancers. Science 253: 49-53.

36. Hofree M, Shen JP, Carter H, Gross A, Ideker T (2013) Network-based stratification of tumor mutations. Nat Methods 10: 1108-1115.

37. Ananthula S, Sinha A, El Gassim M, Batth S, Marshall GD, et al. (2016) Geminin overexpression-dependent recruitment and crosstalk with mesenchymal stem cells enhance aggressiveness in triple negative breast cancers. Oncotarget 7: 20869.

38. Hosain SB, Khiste SK, Uddin MB, Vorubindi V, Ingram C, et al. (2016) Inhibition of glucosylceramide synthase eliminates the oncogenic function of p53 R273H mutant in the epithelial-mesenchymal transition and induced pluripotency of colon cancer cells. Oncotarget 7: 60575-60592.

39. Chan KK, Oza AM, Siu LL (2003) The statins as anticancer agents. Clin Cancer Res 9: 10-19.

40. Ananthula S, Parajuli P, Behery FA, Alayoubi AY, El Sayed KA (2014) Oxazine derivatives of ?-and d-tocotrienol display enhanced anticancer activity in vivo. Anticancer Res 34: 2715-2726.

41. Ananthula S, Parajuli P, Behery FA, Alayoubi AY, Nazzal S, et al. (2014) $\mathrm{Y}$-Tocotrienol oxazine derivative antagonizes mammary tumor cell compensatory response to $\mathrm{CoCl}_{2}$-induced hypoxia. Biomed Res Int 285752 .

42. Ali H, Shirode AB, Sylvester PW, Nazzal S (2010) Preparation, characterization, and anticancer effects of simvastatin-tocotrienol lipid nanoparticles. Int $\mathrm{J}$ Pharmaceut 389: 223-231.

43. Wali VB, Sylvester PW (2007) Synergistic antiproliferative effects of $y$-tocotrienol and statin treatment on mammary tumor cells. Lipids 42: 1113-1123.

44. Wali VB, Bachawal SV, Sylvester PW (2009) Suppression in mevalonate synthesis mediates antitumor effects of combined statin and $\mathrm{y}$-tocotrienol treatment. Lipids 44: 925

45. Buckley MF, Sweeney KJ, Hamilton JA, Sini RL, Manning DL, et al. (1993) Expression and amplification of cyclin genes in human breast cancer. Oncogene 8: 2127-2133.

46. Yang Z, Xiao H, Jin H, Koo PT, Tsang DJ, et al. (2010) Synergistic actions of atorvastatin with $\gamma$-tocotrienol and celecoxib against human colon cancer HT29 and HCT116 cells. Int J Cancer 126: 852-863.

47. Sylvester PW, Akl MR, Malaviya A, Parajuli P, Ananthula S, et al. (2014) Potential role of tocotrienols in the treatment and prevention of breast cancer. Biofactors 40: 49-58.

48. Noguchi Y, Nakamura S, Yasuda T, Kitagawa M, Kohn LD, et al. (1998) Newly synthesized Rho A, not Ras, is isoprenylated and translocated to membranes coincident with progression of the $\mathrm{G} 1$ to $\mathrm{S}$ phase of growth-stimulated rat FRTL-5 cells. J Bio Chem 273: 3649-3653.

49. Tsujii M, Kawano S, DuBois RN (1997) Cyclooxygenase-2 expression in human colon cancer cells increases metastatic potential. Proc Natl Acad Sci 94 : 3336-3340.

50. Sheng H, Shao J, Morrow JD, Beauchamp RD, DuBois RN (1998) Modulation of apoptosis and $\mathrm{Bcl}-2$ expression by prostaglandin E2 in human colon cancer cells. Cancer Res 58: 362-366.

51. Grösch S, Maier TJ, Schiffmann S, Geisslinger G (2006) Cyclooxygenase-2 (COX-2)-independent anticarcinogenic effects of selective COX-2 inhibitors. J Natl Cancer Inst 98: 736-747.

52. Rosenberg L, Palmer JR, Zauber AG, Warshauer ME, Stolley PD, et al. (1991) A hypothesis: nonsteroidal anti-inflammatory drugs reduce the incidence of large-bowel cancer. J Natl Cancer Inst 83: 355-358.

53. Thun MJ, Namboodiri MM, Calle EE, Flanders WD, Heath CW (1993) Aspirin use and risk of fatal cancer. Cancer Res 53: 1322-1327.
54. Muscat JE, Stellman SD, Wynder EL (1994) Nonsteroidal anti-inflammatory drugs and colorectal cancer. Cancer 74: 1847-1854.

55. Solomon SD, McMurray JJ, Pfeffer MA, Wittes J, Fowler R, et al. (2005) Cardiovascular risk associated with celecoxib in a clinical trial for colorectal adenoma prevention. N Engl J Med 352: 1071-1080.

56. Psaty BM, Potter JD (2006) Risks and benefits of celecoxib to prevent recurrent adenomas. N Engl J Med 355: 950-952.

57. Winde G, Gumbinger HG, Osswald H, Kemper F, Bünte H (1993) The NSAID sulindac reverses rectal adenomas in colectomized patients with familial adenomatous polyposis: clinical results of a dose-finding study on rectal sulindac administration. Int J Colorectal Dis 8: 13-17.

58. Xiao H, Yang CS (2008) Combination regimen with statins and NSAIDs: a promising strategy for cancer chemoprevention. Int J Cancer 123: 983-990.

59. Flick ED, Habel LA, Chan KA, Van Eeden SK, Quinn VP, et al. (2007) Statin use and risk of prostate cancer in the California Men's Health Study cohort. Cancer Epi Preven Biomar 16: 2218-2225.

60. Zheng X, Cui XX, Avila GE, Huang MT, Liu Y, et al. (2007) Atorvastatin and celecoxib inhibit prostate PC-3 tumors in immunodeficient mice. Clin Cancer Res 13: 5480-5487.

61. Reddy BS, Wang CX, Kong AN, Khor TO, Zheng X, et al. (2006) Prevention of azoxymethane-induced colon cancer by combination of low doses of atorvastatin, aspirin, and celecoxib in F 344 rats. Cancer Res 66: 4542-4546.

62. Xiao H, Zhang Q, Lin Y, Reddy BS, Yang CS (2008) Combination of atorvastatin and celecoxib synergistically induces cell cycle arrest and apoptosis in colon cancer cells. Int J Cancer 122: 2115-2124.

63. Martirosyan A, Clendening JW, Goard CA, Penn LZ (2010) Lovastatin induces apoptosis of ovarian cancer cells and synergizes with doxorubicin: potential therapeutic relevance. BMC Cancer 10: 103

64. Stein WD (1997) Kinetics of the multidrug transporter (P-glycoprotein) and its reversal. Physiol Rev 77: 545-590.

65. Bogman K, Peyer AK, Török M, Küsters E, Drewe J (2001) HMG-CoA reductase inhibitors and P-glycoprotein modulation. Br J Pharmacol 132: 1183-1192.

66. Wang E, Casciano CN, Clement RP, Johnson WW (2001) HMG-CoA reductase inhibitors (statins) characterized as direct inhibitors of P-glycoprotein Pharmaceut Res 18: 800-806.

67. Sieczkowski E, Lehner C, Ambros PF, Hohenegger M (2010) Double impact on p-glycoprotein by statins enhances doxorubicin cytotoxicity in human neuroblastoma cells. Int J Cancer 126: 2025-2035.

68. Connelly-Smith L, Pattinson J, Grundy M, Shang S, Seedhouse C, et al. (2007) P-glycoprotein is downregulated in KG1a-primitive leukemia cells by LDL cholesterol deprivation and by HMG-CoA reductase inhibitors. Exp Hemato 35: $1793-1800$

69. Schinkel AH, Kemp S, Dollé M, Rudenko G, Wagenaar E (1993) N-glycosylation and deletion mutants of the human MDR1 P-glycoprotein. J Biol Chem 268 : 7474-7481.

70. Lee J, Hae Jun K, Suk Park J, Bae Ahn J, Jun Shin S (2009) Simvastatin plus irinotecan, 5-fluorouracil, and leucovorin (FOLFIRI) as first-line chemotherapy in metastatic colorectal patients: a multicenter phase II study. Cancer Chemother Pharmacol 64: 657-663.

71. Platz EA, Leitzmann MF, Visvanathan K, Rimm EB, Stampfer MJ, et al. (2006) Statin drugs and risk of advanced prostate cancer. J Natl Cancer Inst 98: 1819-1825

72. Murtola TJ, Tammela TL, Lahtela J, Auvinen A (2007) Cholesterol-lowering drugs and prostate cancer risk: a population-based case-control study. Cancer Epidemiol Prev Biomark 16: 2226-2232.

73. Cyrus-David MS, Weinberg A, Thompson T, Kadmon D (2005) The effect of statins on serum prostate specific antigen levels in a cohort of airline pilots: a preliminary report. J Urol 173: 1923-1925.

74. Hamilton RJ, Goldberg KC, Platz EA, Freedland SJ (2008) The influence of statin medications on prostate-specific antigen levels. J Natl Cancer Inst 100: 1511-1518.

75. Zhuang L, Kim J, Adam RM, Solomon KR, Freeman MR (2005) Cholestero targeting alters lipid raft composition and cell survival in prostate cancer cells and xenografts. J Natl Cancer Inst 115: 959-968. 